OPEN ACCESS

Edited by:

Takayuki Yoshimoto,

Tokyo Medical University, Japan

Reviewed by:

Kiyoshi Hirahara,

Chiba University, Japan

Eleni Papakonstantinou, Aristotle University of Thessaloniki,

Greece

*Correspondence:

Maria Jose Campagnole-Santos mjcs@icb.ufmg.br

tThese authors have contributed equally to this work.

Specialty section:

This article was submitted to Inflammation,

a section of the journal

Frontiers in Immunology

Received: 06 November 2017

Accepted: 09 January 2018

Published: 29 January 2018

Citation:

Magalhaes GS, Barroso LC, Reis AC,

Rodrigues-Machado MG,

Gregório JF, Motta-Santos D, Oliveira AC, Perez DA, Barcelos LS, Teixeira MM, Santos RAS, Pinho V and Campagnole-Santos MJ (2018)

Angiotensin-(1-7) Promotes

Resolution of Eosinophilic

Inflammation in an Experimental Model of Asthma.

Front. Immunol. 9:58.

doi: 10.3389/fimmu.2018.00058

\section{Angiotensin-(1-7) Promotes Resolution of Eosinophilic Inflammation in an Experimental Model of Asthma}

Giselle S. Magalhaes ${ }^{1 t}$, Livia C. Barroso ${ }^{2 t}$, Alesandra C. Reis ${ }^{3}$, Maria G. RodriguesMachado', Juliana F. Gregório', Daisy Motta-Santos ${ }^{1}$, Aline C. Oliveira', Denise A. Perez ${ }^{3}$, Lucíola S. Barcelos', Mauro M. Teixeira ${ }^{2}$, Robson A. S. Santos ${ }^{1}$, Vanessa Pinho ${ }^{3}$ and Maria Jose Campagnole-Santos ${ }^{1 *}$

${ }^{1}$ Department of Physiology and Biophysics, Biological Sciences Institute, Federal University of Minas Gerais, Belo Horizonte, Brazil, ${ }^{2}$ Department of Biochemistry and Immunology, Biological Sciences Institute, Federal University of Minas Gerais, Belo Horizonte, Brazil, ${ }^{3}$ Department of Morphology, Biological Sciences Institute, Federal University of Minas Gerais, Belo Horizonte, Brazil

Defective apoptosis of eosinophils, the main leukocyte in the pathogenesis of asthma, and delay in its removal lead to lung damage and loss of pulmonary function due to failure in the resolution of inflammation. Here, we investigated the ability of angiotensin-(1-7) [Ang-(1-7)], a pivotal peptide of the renin-angiotensin system, to promote resolution of an allergic lung inflammatory response. Balb/c mice were sensitized and challenged with ovalbumin and treated with Ang-(1-7) at the peak of the inflammatory process. Bronchoalveolar lavage (BAL) fluid and lungs were collected $24 \mathrm{~h}$ after treatment. Different lung lobes were processed for histology to evaluate inflammatory cell infiltration, airway and pulmonary remodeling, total collagen staining, and measurements of (i) collagen I and III mRNA expression by qRT-PCR; (ii) ERK1/2, $\iota_{\kappa} \mathrm{B}-\alpha$, and GATA3 protein levels by Western blotting; and (iii) eosinophilic peroxidase activity. Total number of inflammatory cells, proportion of apoptotic eosinophils and immunofluorescence for caspase 3 and $\mathrm{NF}-\kappa \mathrm{B}$ in leukocytes were evaluated in the BAL. Mas receptor immunostaining was evaluated in mouse and human eosinophils. Engulfment of human polimorphonuclear cells by macrophages, efferocytosis, was evaluated in vivo. Ang-(1-7) reduced eosinophils in the lung and in the BAL, increased the number of apoptotic eosinophils, shown by histology criteria and by increase in caspase 3 immunostaining. Furthermore, Ang-(1-7) decreased NF-kB immunostaining in eosinophils, reduced GATA3, ERK1/2, and $1 \kappa B-\alpha$ expression in the lung and decreased pulmonary remodeling and collagen deposition. Importantly, Ang-(1-7) increased efferocytosis. Our results demonstrate, for the first time, Ang-(1-7) activates events that are crucial for resolution of the inflammatory process of asthma and promotion of the return of lung homeostasis, indicating Ang-(1-7) as novel endogenous inflammation-resolving mediator.

Keywords: Mas receptor, apoptosis, efferocytosis, caspase 3, GATA3, NF-kB, lung remodeling, allergic lung inflammation 


\section{INTRODUCTION}

Resolution of inflammation is an active process that allows cessation of inflammation and re-establishment of tissue homeostasis (1-3). It is a process characterized by prevention of excessive trafficking of leukocytes to the site of damage, shutdown intracellular signaling molecules associated with cytokine production and leukocyte survival, induction of apoptosis of recruited inflammatory cells, and promotion of clearance of apoptotic leukocytes, i.e., efferocytosis (1-5).

In chronic inflammatory diseases, including asthma, failure to resolve the inflammatory process causes a persistent inflammation with consequent tissue destruction and loss of organ function (6). In this context, maintenance of inflammation alters pulmonary homeostasis and culminates with clinical manifestations that affect quality of life of asthmatic patients (7). It has been suggested that drugs that enhance resolution of inflammation can be useful for treatment of chronic inflammatory diseases, such as asthma $(2,4,8)$.

Asthma is characterized by inflammation, pulmonary remodeling, and bronchial hyperresponsiveness, in which multiple cells and multiple mediators play a crucial pathophysiological role $(7,9-11)$. Inflammatory mediators that increase influx of leukocytes, activity, and survival of eosinophils are positively correlated with asthma severity $(6,12,13)$. The large increase in incidence of asthma is becoming a major global health problem and has encouraged studies aimed at increasing the knowledge of the pathophysiology of asthma, as well as development of new treatments to improve clinical management of the disease, mainly to meet asthma patients who do not respond well to current therapies (14).

Angiotensin-(1-7) [Ang-(1-7)] is now recognized as an important mediator of the renin-angiotensin system (15). Ang-(1-7) can be synthesized in the circulation or in different tissues mainly by angiotensin-converting enzyme 2 (ACE2) $(16,17)$ and it exerts its actions largely through activation of Mas-G-protein-coupled receptor (18). ACE2/Ang-(1-7)/Mas receptor pathway has gained much interest in recent years because of its anti-inflammatory, anti-proliferative, and anti-fibrotic actions, which oppose to the well-known pro-inflammatory effects of the ACE/Ang II/AT 1 receptor pathway (19).

Recently, we showed that Ang-(1-7) is reduced in the lung of animals with chronic allergic lung inflammation (20). In addition, we demonstrated that preventive administration of Ang-(1-7) or a synthetic analog, AVE0991, greatly attenuate lung inflammation and ameliorated pulmonary function in a model of chronic asthma induced by repeated exposure of immunized mice to ovalbumine $(20,21)$. Activation of ACE2/Ang-(1-7)/Mas axis has also been described to display anti-inflammatory action in other experimental models, including ischemic stroke (22), atherosclerosis (23), pulmonary fibrosis (24), acute lung injury (25), and arthritis (26). On the other hand, in Mas-deficient mice, inflammation was not only enhanced but also prolonged $(26,27)$, suggesting that resolution of inflammation may be altered in the absence/malfunction of the ACE2/Ang-(1-7)/Mas axis.

In this study, we evaluated the potential of oral and intranasal formulation of Ang-(1-7) to promote resolution of inflammation in a model of allergic lung inflammation. Our results clearly show that Ang-(1-7) interferes with the molecular pathways that regulate leukocyte survival and clearance, and promotes resolution of inflammation by driving apoptosis of eosinophils.

\section{MATERIALS AND METHODS}

\section{Animals}

Male BALB/C mice from the Animal Facility of our Institution (Centro de Bioterismo-CEBIO, UFMG) were housed under a $12 / 12 \mathrm{~h}$ light-dark cycle (lights on at $06: 00 \mathrm{~h}$ ) with free access to standard chow and tap water. Mice (8-9 weeks of age, weighing 20-25 g) were randomly assigned to four groups: (i) salinesensitized and saline-challenged, control group (CTRL; $n=15$ ); (ii) ovalbumin (OVA)-sensitized and OVA-challenged group (OVA; $n=15$ ); (iii) OVA-sensitized and OVA-challenged group treated by oral administration of Ang-(1-7)/hydroxypropyl $\beta$-cyclodextrin (HP $\beta C D$ ) [OVA + Ang-(1-7); $n=15]$; and (iv) OVA-sensitized and OVA-challenged group treated by intranasal administration of Ang-(1-7)/HP 3 CD [OVA + Ang-(1-7); $n=10]$. All experimental procedures were approved by the Ethics Committee for Animal Experimentation (CEUA) of the Federal University of Minas Gerais (UFMG), Brazil (Protocol\# 309/2013).

\section{Induction of Asthma}

Sensitization was made by two injections of OVA $(100 \mu \mathrm{g}$ per mouse, i.p.; Sigma, St. Louis, MO, USA) in 2\% alum (aluminum hydroxide gel adjuvant; Brenntag) at 7-days interval (days 0 and 7). Challenge was made by 8 intranasal administration of $10 \mu \mathrm{g}$ of OVA from days 12 to 19 . CTRL group received PBS $(0.2 \mathrm{~mL} /$ mouse, i.p. $)$ and was challenged with PBS at the same time points.

\section{Ang-(1-7) Treatment}

Inclusion of Ang-(1-7) into an oligosaccharide HP $\beta C D$ cavity protects the peptide during its passage through the gastrointestinal tract (28). Therefore, in this study Ang-(1-7)/HP $\beta C D$ inclusion compound was used to perform oral or nasal administration of Ang-(1-7), $24 \mathrm{~h}$ after the last OVA challenge. For oral administration, CTRL and OVA groups received vehicle (92 $\mu \mathrm{g} / \mathrm{Kg}$ of HP $\beta C D$ in distilled water; $100 \mu \mathrm{l}$, by gavage) and OVA+Ang-(1-7) group received Ang-(1-7)/HP $\beta C D$ [60 $\mu \mathrm{g} / \mathrm{Kg}$ of Ang-(1-7) and $92 \mu \mathrm{g} / \mathrm{Kg}$ of HP $\beta C D$ in distilled water; $100 \mu \mathrm{l}$, by gavage]. For intranasal administration, mice received Ang-(1-7)/ $\mathrm{HP} \beta \mathrm{CD}[30 \mu \mathrm{g} / \mathrm{Kg}$ of the Ang-(1-7) and $46 \mu \mathrm{g} / \mathrm{Kg}$ of HP $\beta \mathrm{CD}$ in saline, $20 \mu \mathrm{l}$; OVA+Ang-(1-7) group] and CTRL and OVA groups received vehicle $[46 \mu \mathrm{g} / \mathrm{Kg}$ of $\mathrm{HP} \beta C D$ in saline, $20 \mu \mathrm{l}$ ].

\section{Bronchoalveolar Lavage (BAL) and Lung Samples}

Twenty-four hours after Ang-(1-7) treatment, mice were killed by anesthetic overdose and the trachea of each animal was exposed and cannulated with a polypropylene catheter $(20 \mathrm{G})$. Airways were washed with $2 \mathrm{ml}$ of ice-cold PBS. The 
trachea was then clamped and the lungs were collected in functional residual capacity. Left lung was collected for morphometric analysis and the right lung was removed, snap frozen in dry ice and kept at $-80^{\circ} \mathrm{C}$ until assayed. Total number of leukocytes was counted in Neubauer chamber after staining with Turk's solution. Differential leukocyte counts were performed on cytocentrifuge preparations (Shandon Cytospin III), stained with May-Grünwald-Giemsa and counted using oil immersion microscopy $(\times 100$ objective $)$ using standard morphological criteria to identify cell types. Apoptosis of cells present in the BAL was assessed as described previously (8). Briefly, cells were cytocentrifuged, fixed and stained with May-Grunwald-Giemsa and counted using oil immersion microscopy $(\times 100$ objective $)$ to determine the proportion of cells with distinctive apoptotic morphology (cell shrinkage, chromatin condensation, nuclear fragmentation, and disruption of cell membrane). At least 500 cells were counted per slide and the results expressed as percentage of cells with apoptotic morphology.

\section{Analysis by Immunofluorescence}

Cells of BAL were centrifuged at $1.200 \mathrm{rpm}$ for $5 \mathrm{~min}$ at $4^{\circ} \mathrm{C}$, and the pellet was resuspended in PBS and total cell counts were performed. A total number of $5 \times 10^{5}$ cells was taken to perform cytocentrifugation (Cytospin; Shandon Lipshaw Inc., PA, USA) in cell coverslips. Next, cells were fixed with $4 \%$ paraformaldehyde for 15 min and washed three times. Fc Block (CD16/32, BD Biosciences) was added for 30 min to block unspecific binding of antibody. To evaluate levels of NF- $\kappa \mathrm{B}$ (P-p65) and caspase 3 , cells were permeated for $30 \mathrm{~min}$ with Perm/Wash solution (1:12 in PBS-BSA 1\%; BD Bioscience, USA) and incubated with antibody overnight. For Mas receptor, cells were incubated with primary antibody overnight. Next, cells were incubated with fluorescent secondary antibody (Alexa Fluor 488-Cell Signaling; 1:300; green). For extracellular staining, the antibody was added directly to cells. Negative controls were obtained by performing the assay in the absence of antibody. Finally, coverslips were mounted with Fluormount mounting medium (Sigma-Aldrich, USA) for analysis. Images were obtained in a Nikon Eclipse Ti microscope with laser confocal C2, equipped with three different lasers (excitation 405, 488, and $543 \mathrm{~nm}$ ) and emission filter $450 / 50 \mathrm{~nm}$ (channel 1), 515/30 nm (channel 2), and 584/50 nm (channel 3). Fluorescence intensity was measured using a 6.3 Volocity software (Perkin-Elmer, USA), which calculates the mean of the fluorescence intensity (MFI) of around 30 cells for each animal. Antibodies used were as follows: Pp65-Alexa Fluor 488 (Cell Signaling; 1:100; green), the fluorescent nuclear marker propidium iodide (Cell Signaling; 1:1,000; red), Siglec-F (Santa Cruz; 1:100; blue), cleaved-caspase 3-Alexa Fluor 488 (Cell Signaling; 1:50; green), and Mas receptor (1:100; Alomone; green).

\section{Histological Analysis}

Lung was prepared for histological analysis, as previously described (20). Peribronchial fibrosis was evaluated in lung sections $(4 \mu \mathrm{m})$ stained with trichrome of Gömori (Trichrome Stain
LG Solution; Sigma-Aldrich, USA). Digital images of airways obtained at $200 \times$ magnification were analyzed using the software Image-Pro Plus. Ten to twelve peribronchial areas per lung were outlined and quantified. Results are expressed as the percentage of extracellular matrix deposition area.

\section{Collagen I and III mRNA Expression}

Real-time RT-PCR was performed to evaluate mRNA expression of collagen type I and III in the lung, as previously described (20). Briefly, total RNA from lung sample was extracted using TRIzol reagent (Invitrogen, San Diego, CA, USA), treated with DNAse (RNase-free; Invitrogen) and reverse transcribed with Moloney Murine Leukemia Virus Reverse Transcriptase (M-MLV RT; Promega, Madison, WI, USA). Endogenous GAPDH (internal control), collagen I and collagen III cDNA were amplified using specific primers (Table S1 in Supplementary Material) and SYBR green reagent (Applied Biosystems, CA, USA) in ViiA ${ }^{\mathrm{TM}}$ 7 System (Applied Biosystems, CA, USA). Relative comparative CT method was applied to compare gene expression levels between groups using the equation $2^{-\Delta \Delta C T}$.

\section{Proteins Measured by Western Blotting}

Samples of protein $(50 \mu \mathrm{g})$ extracted from the lung $(n=4-5$ from each group) were applied to polyacrylamide gel/SDS $10 \%$ and then transferred to nitrocellulose membranes. Membranes were incubated overnight with different primary antibodies: GATA3 (Rabbit anti-GATA3, 1:500, Abcam Labs, Cambridge, UK); total $\operatorname{Ik} \beta \alpha$ (rabbit anti-t-IkB $\alpha ; 1: 1,000$; Cell Signaling, MA, USA) or phosphorylated $\mathrm{IkB} \alpha$ (rabbit anti-p-Ik $\beta \alpha ; 1: 500$; Cell Signaling, MA, USA); total ERK1/2 (rabbit anti-t-ERK1/2; 1:1,000; Cell Signaling; MA, USA), or phosphorylated ERK1/2 (rabbit antip-ERK1/2, 1:500; Cell Signaling; MA, USA). Next, membranes were incubated with fluorescent secondary antibody [IRDye ${ }^{\circledR} 680$ conjugated goat (polyclonal) anti-Rabbit $\operatorname{IgG}(\mathrm{H}+\mathrm{L})$ diluted to 1:10,000 (Li-COR Biosciences, NE, USA)]. Levels were normalized to GAPDH levels in the same sample. Staining was visualized and quantified in a Li-COR Odyssey Scanner (Biosciences, NE, USA).

\section{Quantification of Eosinophil Accumulation in Lung}

Pulmonary eosinophil peroxidase (EPO) activity was determined to estimate eosinophil recruitment to the lung parenchyma, as described elsewhere (29). Absorbance was read in an ELISA reader (Expert Plus ASYS Hitech GmbH, Eugenorf, Austria) at $492 \mathrm{~nm}$. Values are expressed in optical density.

\section{Efferocitosys Assay In Vivo}

Human polimorphonuclear cells (PMNs) were isolated from peripheral venous blood drawn from healthy volunteers (Ethics Committee of the Universidade Federal de Minas Gerais, BrazilInstitutional Review Board Project number 0319.0.203.000-11), after informed written consent, as described elsewhere (30). Briefly, PMNs were separated by gradient centrifugation over Histopaque-1119 and Histopaque-1077 (Sigma-Aldrich, USA) and plated at $5 \times 10^{6}$ cells/well. Apoptosis $(>80 \%)$ was induced 
by staurosporine $(10 \mu \mathrm{M})$ by culturing the PMNs in complete RPMI 1,640 for $1 \mathrm{~h}$ at $37^{\circ} \mathrm{C}$ in $5 \% \mathrm{CO}_{2}$ atmosphere. $\mathrm{FVB} / \mathrm{N}$ mice were treated with Ang-(1-7) (3 $\mu \mathrm{g} /$ mice; ip), $30 \mathrm{~min}$ before PMNs apoptotic cells $\left(4 \times 10^{6}\right.$ cells $)$ were injected in animals bearing a $72 \mathrm{~h}$ peritonitis elicited by $0.1 \mathrm{mg}$ of zymosan. Mice were killed after $3 \mathrm{~h}$ and exudates were collected for morphologic analysis of the percentage of macrophages containing apoptotic PMNs (31).

\section{Statistical Analysis}

Results are expressed as mean \pm SEM. Comparisons among three or more groups were performed by one-way ANOVA followed by Newman-Keuls post hoc test. Significance between two groups was assessed by Student $t$-test. All analysis and graphics were made with the GraphPad Prism software (version 5.0; La Jolla, CA, USA). The level of significance was set to $p<0.05$.

\section{RESULTS}

\section{Treatment with Ang-(1-7) Decreased Eosinophil Accumulation}

Considering the majority of Ang-(1-7) actions described to date are mediated by Mas receptor $(18,19)$, using immunofluorescence, we first showed that Mas receptor is indeed present in both murine (Figure 1A) and human (Figure S1 in Supplementary Material) eosinophils.

Next, we treated mice with oral administration of the inclusion compound, Ang-(1-7)/HP $\beta C D, 24 \mathrm{~h}$ after the last OVA challenge, a time point at which the number of eosinophils are maximal and neutrophils are close to baseline (8). As expected, challenge with OVA induced an increase in the number of total cells in BAL (Figure 1B) and eosinophils (Figure 1C). Ang-(1-7) significantly decreased the number of eosinophils in the BAL of OVA-challenged mice $\left(3 \times 10^{5} \pm 1\right.$ vs $10 \times 10^{5} \pm 2$ cells, in OVA
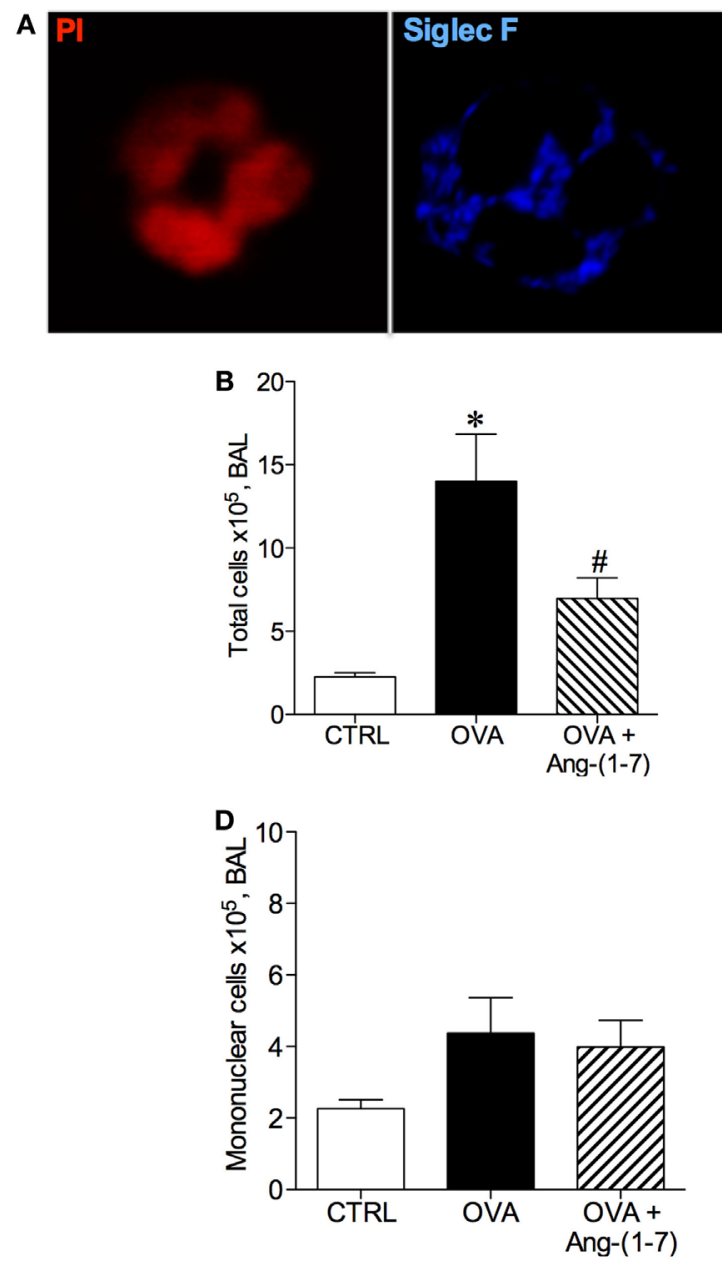
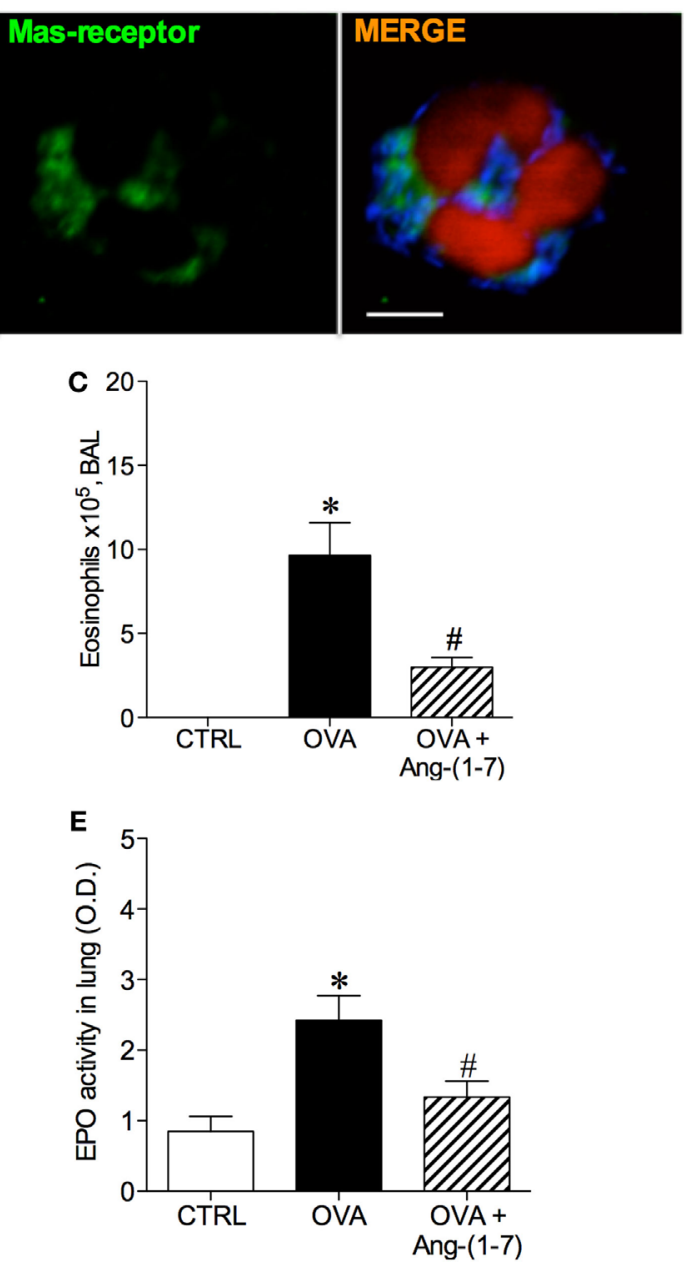

FIGURE 1 | (A) Image of an eosinophil of the bronchoalveolar lavage (BAL) fluid illustrating Mas receptor expression by immunofluorescence; propidium iodide (PI), a marker of nucleus cell, in red; siglec F, a marker of eosinophil, in blue; and Mas receptor in green; Scale = $5 \mu \mathrm{m}$; (B) Number of total cells in the BAL; (C) Number of eosinophils in the BAL; (D) Number of mononuclear cell in the BAL; (E) Eosinophilic peroxidase (EPO) activity in the lung of control (CTRL), asthmatic (OVA) and asthmatic mice treated with oral administration of Ang-(1-7)/hydroxypropyl $\beta$-cyclodextrin (HP $\beta C D)[60 \mu g / k g$ of Ang-(1-7) and $92 \mu \mathrm{g} / \mathrm{kg}$ of HP $\beta C D]$. Bars show mean \pm SEM from five to six animals per group. ${ }^{\star} p \leq 0.05$ compared to CTRL and ${ }^{\sharp} p \leq 0.05$ compared to OVA (one-way ANOVA followed by Newman-Keuls test). 
group, Figure 1B), without altering the number of mononuclear cell (Figure 1D). Similar results were observed with intranasal administration Ang-(1-7) (Figure S2 in Supplementary Material). In keeping, oral Ang-(1-7) treatment also reduced the level of EPO activity in the lung (Figure 1E).

\section{Angiotensin-(1-7) Promoted Resolution of Inflammation by Inducing Eosinophil Apoptosis}

Next, we investigated whether oral administration of Ang(1-7) could induce apoptosis of eosinophils, an important action to promote resolution of the inflammation. As shown in Figure 2A, Ang-(1-7) treatment increased the number of apoptotic eosinophils, as assessed by morphological criteria. Indeed, apoptosis of eosinophils was confirmed by a marked increase in caspase 3 expression in these cells (Figures 2B,C). This effect was also observed after intranasal administration of Ang-(1-7) (Figures S3A,B in Supplementary Material).

Following this observation, we investigated whether Ang(1-7) could increase the ability of macrophages to engulf apoptotic leukocytes, a process referred as efferocytosis. Treatment with Ang-(1-7) induced a significant increase in efferocytosis of apoptotic PMNs cells (15.0 \pm 1.4 vs $3.8 \pm 1.2 \%$, untreated mice).

\section{Angiotensin-(1-7) Promoted Resolution of Inflammation by Inhibition of the Survival of Eosinophils}

Treatment with Ang-(1-7) decreased NF- $\kappa B$ staining in eosinophils of OVA-immunized and challenged mice $(884 \pm 23.3$ vs $1,084 \pm 29.2$ MFI, OVA group; Figures 3A,B). This result points

C
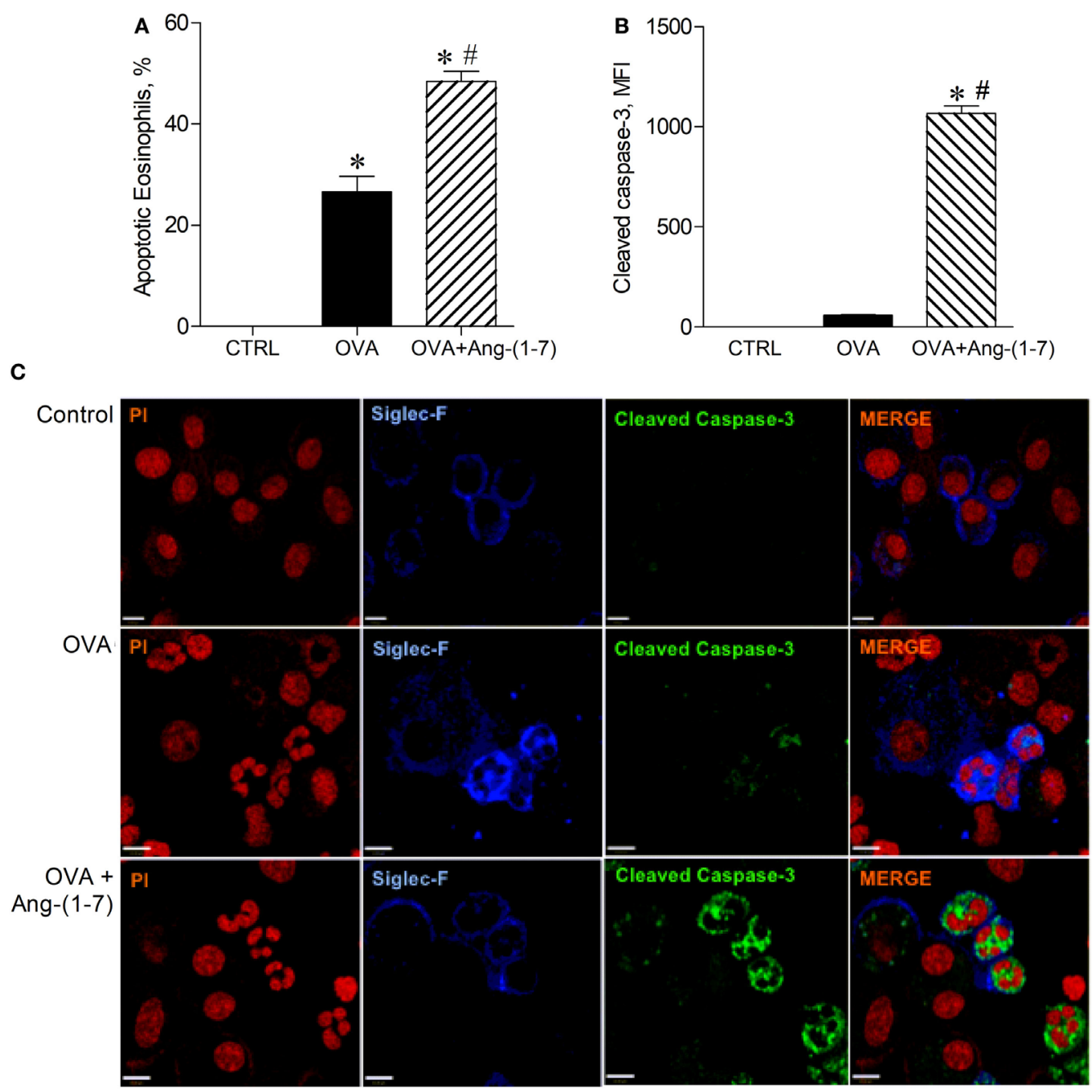

FIGURE 2 | (A) Percentage of apoptotic eosinophils evaluated by morphological criteria in the bronchoalveolar lavage (BAL); (B) cleaved caspase 3 in eosinophils evaluated by immunofluorescence; (C) images illustrating cleaved caspase 3 immunofluorescence in eosinophils in the BAL; in control (CTRL), asthmatic (OVA), and

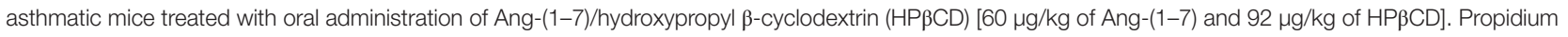
iodide (PI), a marker of nucleus cell, in red; siglec F, a marker of eosinophil, in blue; and cleaved caspase 3 in green. MFI = mean fluorescence intensity. Scale $=43 \mu \mathrm{m}$. Bars show mean \pm SEM from five to six animals per group. ${ }^{\star} p \leq 0.05$ compared to CTRL and ${ }^{*} p \leq 0.05$ compared to OVA (One-way ANOVA followed by Newman-Keuls test). 

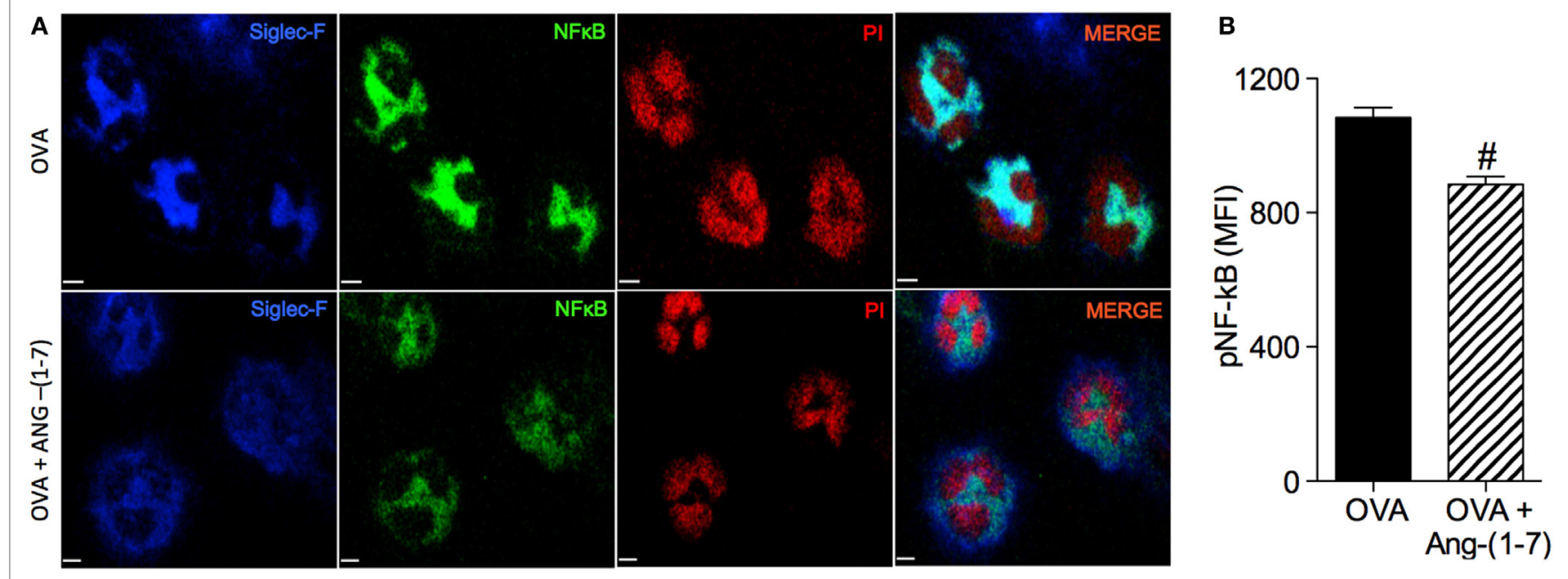

FIGURE 3 | (A) Images showing phosphorylated NF-кB immunofluorescence in eosinophils in the bronchoalveolar lavage (BAL); (B) phosphorylated NF- $\mathrm{KB}$ in eosinophils evaluated by immunofluorescence; in asthmatic (OVA) and asthmatic mice treated with oral administration of Ang-(1-7)/hydroxypropyl $\beta$-cyclodextrin

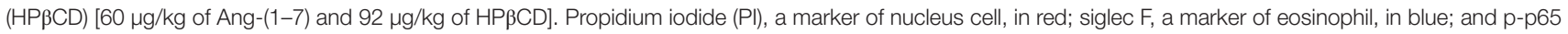
in green. $\mathrm{MFI}=$ mean fluorescence intensity. Scale $=15 \mu \mathrm{m}$. Bars show mean \pm SEM from five to six animals per group. ${ }^{\#} p \leq 0.05$ compared to asthmatic untreated mice (OVA; Student's t-test).

to one mechanism, importantly involved in the survival of leukocytes at the site of injury, by which Ang-(1-7) may resolve eosinophilic inflammation.

\section{Resolution of Allergic Lung Inflammation was Associated with Decreased Expression of ERK1/2, IкB- $\alpha$, and GATA3 in the Lung}

Oral treatment with Ang-(1-7) significantly attenuated the increase in the phosphorylation of $\mathrm{I \kappa B}-\alpha(0.418 \pm 0.03$; Figure 4A) observed in OVA-challenged mice $(0.771 \pm 0.06)$. No significant difference in total I $\mathrm{B}$ - $\alpha$ was observed (data not shown).

Treatment with Ang-(1-7) greatly reduced the level of ERK1/2 phosphorylation in OVA-challenged animals $(0.368 \pm 0.05$ vs $0.836 \pm 0.08$, OVA group; Figure 4B). No significant difference in total ERK1/2 was found (data not shown). Furthermore, oral treatment with Ang-(1-7) significantly reduced GATA3 expression in the lungs of OVA-challenged mice (Figure 4C). Similar results were observed with intranasal administration of Ang-(1-7) (Figures S4A-C in Supplementary Material). These data show that Ang-(1-7), given by oral or intranasal route,

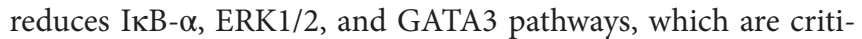
cal for immune cell migration, survival, differentiation, and the synthesis of pro-inflammatory mediators.

\section{Ang-(1-7) Decreased Expression of Early Markers of Fibrogenesis}

We have next assessed whether treatment with Ang-(1-7) could restore lung homeostasis. Figures $\mathbf{5 A - C}$ shows representative images of the lung showing asthma-induced alterations in extracellular matrix deposition. OVA-sensitized and challenged mice treated with oral administration of Ang-(1-7)/HP $\beta$ CD had a marked reduction in extracellular matrix deposition in airway walls and alveolar parenchyma (Figures 5C,D). Furthermore, Ang-(1-7) treatment induced a marked decrease in collagen I (Figure 5E) and collagen III (Figure 5F) mRNA expression in the lung of OVA-challenged mice. Intranasal treatment with Ang(1-7) also reduced extracellular matrix deposition in the lung of OVA-challenged animals (Figure S5 in Supplementary Material).

\section{DISCUSSION}

In this study, we evaluated the effect of Ang-(1-7) administration in the context of inflammatory resolution of allergic lung inflammation, a crucial event that prevents tissue damage and the consequent loss of organ functions $(1,4)$. We demonstrated that treatment with Ang-(1-7), at the peak of inflammation, i.e., after the influx of cells: (i) reduced accumulation of eosinophils in the BAL and in the lung, without altering the number of macrophages; (ii) induced apoptosis of eosinophils, as shown by increased number of apoptotic cells and increased caspase 3 expression in these cells; (iii) decreased NF- $\kappa \mathrm{B}$ phosphorylation; (iv) decreased GATA3, ERK1/2, and I $\kappa$ B- $\alpha$ expression in the lung; and (v) decreased pulmonary remodeling. Furthermore, the presence of Mas receptor was shown, for the first time, in murine and human eosinophils and, Ang-(1-7) was able to induce efferocytosis of human PMNs. Altogether, these results demonstrate a pro-resolutive action of Ang-(1-7) in a model of eosinophilic inflammation.

Studies showed that activation of NF- $\kappa \mathrm{B}$ is the major survival pathway of leukocytes, including eosinophils $(32,33)$. By contrast, inhibition of this pathway was associated with apoptosis of leukocytes and resolution of inflammation (32-34). In asthma, activation of NF- $\kappa \mathrm{B}$ increases expression of genes encoding 

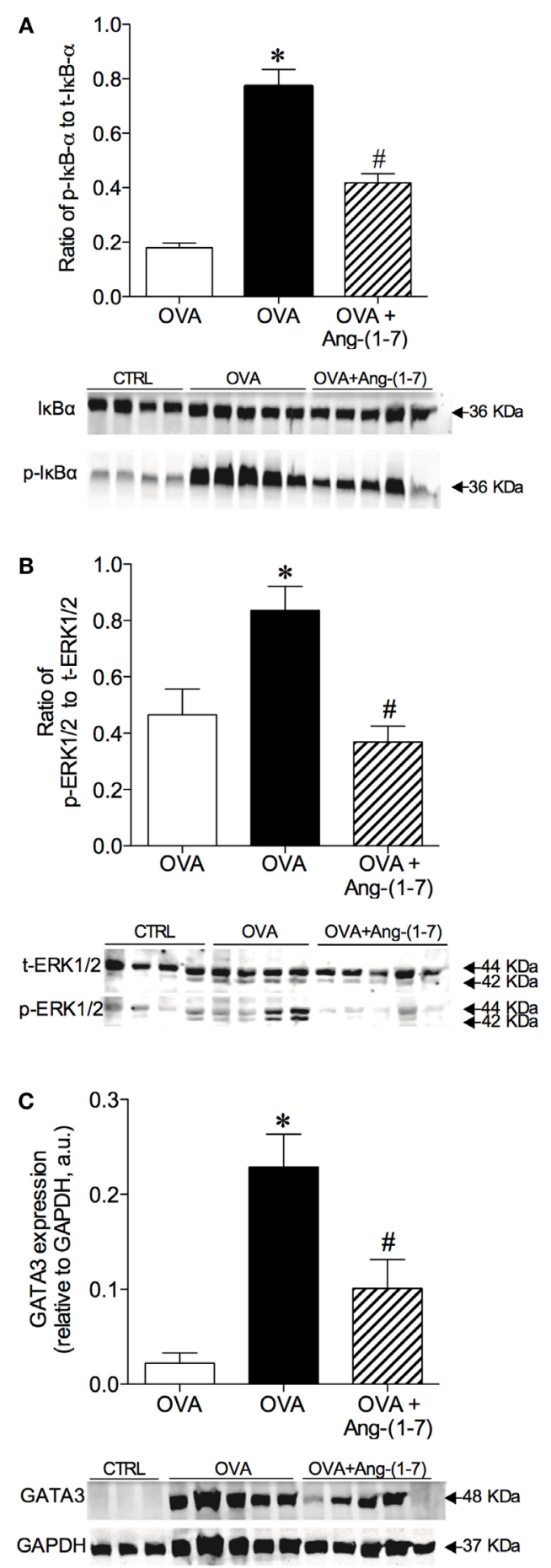

FIGURE 4 | Densitometric quantification by Western blotting of intracellular signaling molecules of control (CTRL), asthmatic (OVA), and asthmatic mice treated with oral administration of Ang-(1-7)/hydroxypropyl $\beta$-cyclodextrin

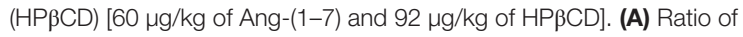
phosphorylated and total $\mathrm{l}_{\kappa} \mathrm{B}-\alpha$; $(\mathbf{B})$ ratio of phosphorylation and total ERK1/2; and (C) GATA3 expression in arbitrary units (a.u) in relation to GAPDH. Bars show mean \pm SEM of 3-5 animals per group. Below each graph are representative blots illustrating molecular weight of each band (in KDa). ${ }^{*} p \leq 0.05$ compared to CTRL; ${ }^{*} p \leq 0.05$ compared to OVA (One-way ANOVA followed by Newman-Keuls). inflammatory cytokines and chemokines, maintaining the recruitment, activation, and survival of inflammatory cells (35, 36). The role of this transcription factor in the pathophysiology of asthma is supported by studies that showed that NF- $\kappa \mathrm{B}$-deficient mice develop only modest allergic lung inflammation (36). In addition, inhibition of NF- $\mathrm{KB}$ attenuates airway inflammation and pulmonary remodeling in a murine model of asthma (35, 36). Our data clearly showed that Ang-(1-7) decreases activation of NF- $\kappa \mathrm{B}$ pathway in eosinophils and in the lung. This result shows that the pro-resolutive action of Ang-(1-7) in inducing leukocyte apoptosis and resolution of the allergic lung

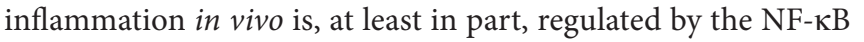
phosphorylation.

Activation of a Th2 response during asthma is known to contribute to eosinophilic infiltration into the lungs, fibrosis, and loss of organ functions $(7,9)$. It has been demonstrated that GATA3 is an essential transcription factor for Th2 development and Th2-driven inflammation (37-39). Activation of ERK1/2 regulates GATA3 stability and Th2 differentiation (38). Treatment with Ang-(1-7) reduced GATA3 and ERK1/2 phosphorylation in the lung in OVA-challenged mice. In acute (35) or chronic asthma (20), decrease in ERK1/2 phosphorylation was associated with anti-inflammatory effect of Ang-(1-7). Therefore, resolution of inflammation induced by Ang-(1-7) was associated not only with a decrease in the number of eosinophils in the lung but also with a decrease in Th2 response at the development or at the chronic stages of the disease.

Increase in apoptosis of leukocytes and their clearance by macrophages are essential events to promote resolution of inflammation $(1,4)$. In a separated set of experiment, using a well-known approach to study efferocytosis in vivo (31), we showed that Ang-(1-7) treatment increased the clearance of the apoptotic cells by macrophages. This result adds an important criteria to establish Ang-(1-7) as an endogenous pro-resolving mediator.

Our results are also in keeping with previous studies that showed that anti-inflammatory, anti-proliferative, and antifibrotic effects of Ang-(1-7) are associated with inhibition of leukocyte migration and cytokine expression (19). Furthermore, Ang-(1-7) was shown to reduce key signaling pathways and molecules thought to be relevant for tissue remodeling (20, $23,24,35)$. In the present study, we provided strong evidence indicating that Ang-(1-7) can induce resolution of inflammation, through stimulation of caspase 3 and attenuation of NF- $\kappa B$ activation downstream mechanisms. Ang-(1-7) induced apoptosis of eosinophils without reducing the number of macrophages in the lung, this observation together with its ability to increase engulfment of apoptotic leukocytes, i.e., efferocytosis, it is important to be highlighted.

Our results showed that treatment with Ang-(1-7) in addition to resolving eosinophilic inflammation, had major physiological consequences in a model of asthma. Treatment with Ang-(1-7) diminished extracellular matrix accumulation and greatly reduced collagen I and III genes expression in the lung, which is of particular interest since collagen deposition in airways contributes to the lack of bronchial response in patients with chronic disease and it leads to severe unresponsive asthma. 


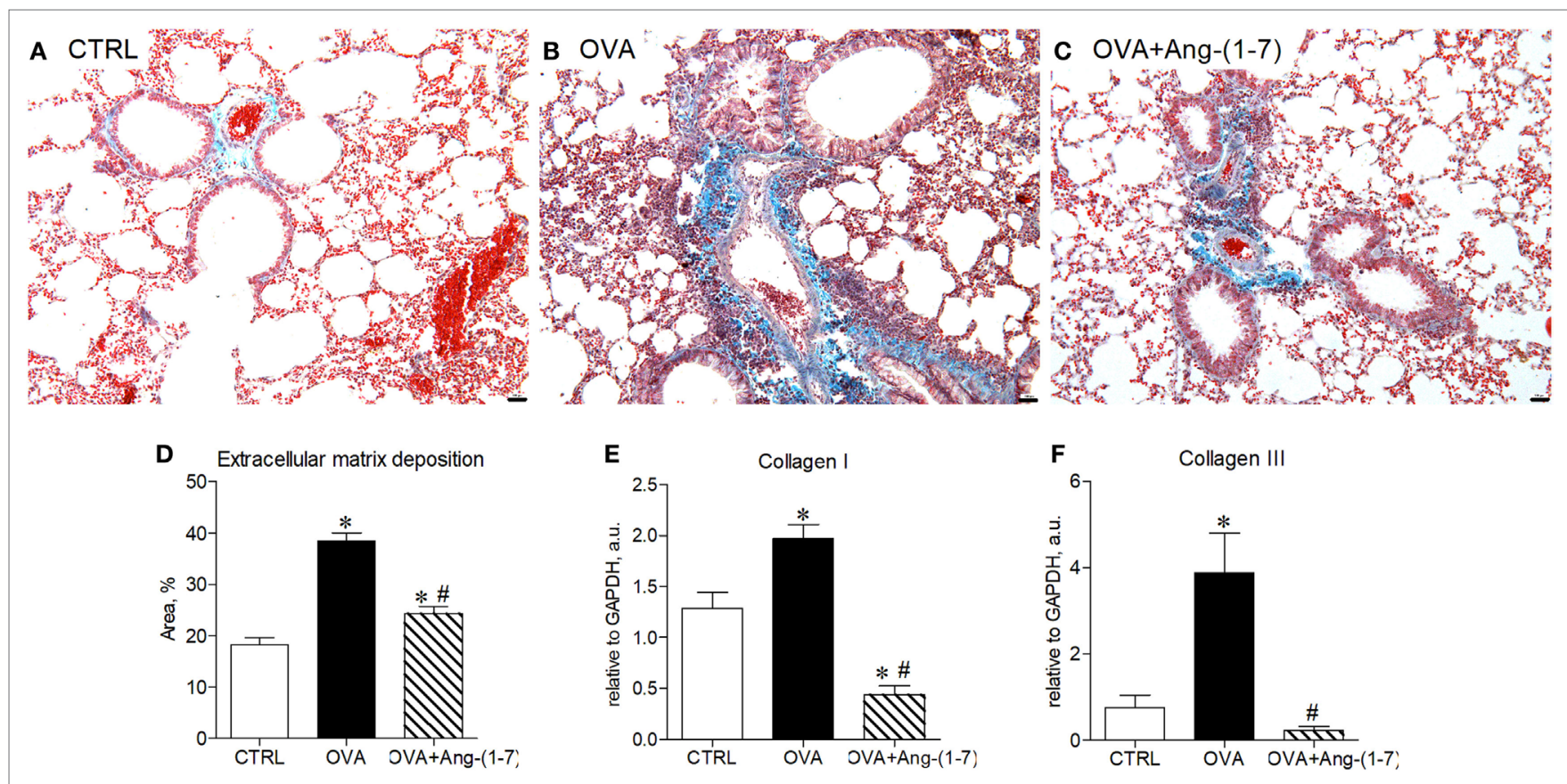

FIGURE 5 | (A-C) Representative images of lung sections stained with trichrome of Gomori from control (CTRL), asthmatic (OVA), and OVA mice treated with oral

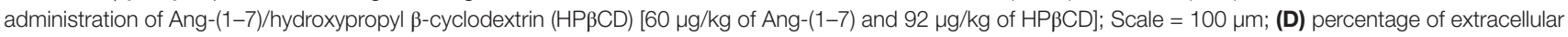
matrix deposition in the lung, evaluated by histology; (E,F) mRNA expression of collagen I and III in the lung. Bars show mean \pm SEM from five to six animals per group. ${ }^{*} p \leq 0.05$ compared to CTRL; ${ }^{*} p \leq 0.05$ compared to OVA (one-way ANOVA followed by Newman-Keuls test).

Unregulated or prolonged inflammatory responses in the lungs can lead to tissue damage, pulmonary remodeling, and consequently compromise lung function $(7,40)$. Ang-(1-7), acting through the Mas receptor, has been shown to attenuate inflammation and fibrosis in different pathophysiological conditions (19). In previous study, treatment with Ang-(1-7) prevented pulmonary remodeling in a model of acute (35) or chronic asthma (20). Moreover, lack of the Mas receptor resulted in an intense degree of lung inflammation and remodeling in mice subjected to experimental model of chronic asthma (27). In present study, Ang-(1-7) induced resolution of inflammation via modulation of eosinophil apoptosis and the phagocytic clearance of apoptotic cells. These effects induced the return of pulmonary homeostasis through a decrease in extracellular matrix accumulation and a great reduction in collagen I and III genes expression in the lung.

Effects induced by Ang-(1-7) were observed either by oral or intranasal administration, which is important also to highlight. However, there are differences to be noted, intranasal dose $(30 \mu \mathrm{g} / \mathrm{kg})$ was half of oral dose $(60 \mu \mathrm{g} / \mathrm{kg})$, and complete resolution after intranasal administration was $24 \mathrm{~h}$ faster than after oral administration (data not shown). These information may favor intranasal administration, similar to standard treatments available. Nevertheless, asthma is not only a lung disease but it is also a systemic disease and correlates with less favorable respiratory function and response to standard treatment (41-44). Taking this into account and, the fact that Ang-(1-7) is an endogenous peptide already passed phase 1 clinical test, oral administration can present additional important advantages. In asthmatic patients, extra-pulmonary comorbidities contribute substantially to poor asthma control. Patients with difficult-to-control asthma also can present rhinitis, chronic rhinosinusitis, gastroesophageal reflux, obstructive sleep apnea, vocal cord dysfunction, obesity, dysfunctional breathing and anxiety/depression (45). Thus, the observation that Ang-(1-7) is effective after oral route can provide clinical benefits for treatment of allergic asthma, as it can be better tolerated than nebulization or than standard drugs, and it can act sistemically reducing overall inflammation and optimizing health of patients.

In conclusion, we unveil a novel action of the peptide Ang(1-7), resolution of allergic lung inflammation. Our data demonstrated that treatment with Ang-(1-7) in mice with allergic lung inflammation fulfills all the criteria to be considered a novel resolution-inducing mediator. Therefore, together with previous findings showing that Ang-(1-7) presents an important antiinflammatory effect, and considering that, it is an endogenous peptide already being subjected to phase 1 clinical trial, these data will accelerate the research efforts for the development of new Ang-(1-7)-based pharmacological strategies to control, prevent, and treat chronic inflammation-related diseases, such as asthma.

\section{ETHICS STATEMENT}

All experimental procedures were approved by the Ethics Committee for Animal Experimentation (CEUA) of the Federal University of Minas Gerais (UFMG), Brazil (Protocol\# 309/2013) and the Ethics Committee of the Universidade Federal de Minas Gerais, Brazil-Institutional Review Board Project number 0319.0.203.000-11. 


\section{AUTHOR CONTRIBUTIONS}

GM and LCB: study conception and design, data acquisition, analysis and interpretation, and drafting and revising the manuscript; MR-M and LSB: data analysis and interpretation, and revising the manuscript; AR, JG, DM-S, AO, and DP: data acquisition, analysis, and interpretation; MT, VP, and RS: study conception and design, data analysis and interpretation, and manuscript edition and revision; MC-S: study conception and design, data analysis and interpretation, drafting, editing, and revising the manuscript. All authors approved the final version of manuscript.

\section{ACKNOWLEDGMENTS}

The authors are thankful to Jose Roberto da Silva and Marilene Luzia Oliveira for technical assistance.

\section{REFERENCES}

1. Perez DA, Vago JP, Athayde RM, Reis AC, Teixeira MM, Sousa LP, et al. Switching off key signaling survival molecules to switch on the resolution of inflammation. Mediators Inflamm (2014) 2014:829851. doi:10.1155/ 2014/829851

2. Vago JP, Nogueira CR, Tavares LP, Soriani FM, Lopes F, Russo RC, et al. Annexin A1 modulates natural and glucocorticoid-induced resolution of inflammation by enhancing neutrophil apoptosis. J Leukoc Biol (2012) 92:249-58. doi:10.1189/jlb.0112008

3. Vago JP, Tavares LP, Garcia CC, Lima KM, Perucci LO, Vieira ÉL, et al. The role and effects of glucocorticoid-induced leucine zipper in the context of inflammation resolution. J Immunol (2015) 194:4940-50. doi:10.4049/ jimmunol.1401722

4. Sugimoto MA, Sousa LP, Pinho V, Perretti M, Teixeira MM. Resolution of inflammation: what controls its onset? Front Immunol (2016) 7:160. doi:10.3389/fimmu.2016.00160

5. Serhan CN. The resolution of inflammation: the devil in the flask and in the details. FASEB J (2011) 25:1441-8. doi:10.1096/fj.11-0502ufm

6. Felton JM, Lucas CD, Rossi AG, Dransfield I. Eosinophils in the lung modulating apoptosis and efferocytosis in airway inflammation. Front Immunol (2014) 5:302. doi:10.3389/fimmu.2014.00302

7. Holgate ST. Asthma: a simple concept but in reality a complex disease. Eur J Clin Invest (2011) 41:1339-52. doi:10.1111/j.1365-2362.2011.02534.x

8. Reis AC, Alessandri AL, Athayde RM, Perez DA, Vago JP, Ávila TV, et al. Induction of eosinophil apoptosis by hydrogen peroxide promotes the resolution of allergic inflammation. Cell Death Dis (2015) 6:e1632. doi:10.1038/ cddis. 2014.580

9. Holgate ST. The airway epithelium is central to the pathogenesis of asthma. Allergol Int (2008) 57:1-10. doi:10.2332/allergolint.R-07-154

10. Jacobsen EA, Helmers RA, Lee JJ, Lee NA. The expanding role(s) of eosinophils in health and disease. Blood (2012) 120:3882-90. doi:10.1182/ blood-2012-06-330845

11. Fulkerson PC, Rothenberg ME. Targeting eosinophils in allergy, inflammation and beyond. Nat Rev Drug Discov (2013) 12:117-29. doi:10.1038/ $\operatorname{nrd} 3838$

12. Wilson SJ, Rigden HM, Ward JA, Laviolette M, Jarjour NN, Djukanovic R. The relationship between eosinophilia and airway remodelling in mild asthma. Clin Exp Allergy (2013) 112:1342-50. doi:10.1111/cea.12156

13. Duncan CJA, Lawrie A, Blaylock MG, Douglas JG, Walsh GM. Reduced eosinophil apoptosis in induced sputum correlates with asthma severity. Eur Respir J (2003) 22:484-90. doi:10.1183/09031936.03.00109803a

14. Loftus PA, Wise SK. Epidemiology and economic burden of asthma. Int Forum Allergy Rhinol (2015) 5(Suppl 1):S7-10. doi:10.1002/alr.21547

\section{FUNDING}

This study was funded by the Conselho Nacional de Desenvolvimento Científico e Tecnológico (CNPq) and Fundação de Amparo à Pesquisa do Estado de Minas Gerais (FAPEMIG) through the INCT-Nanobiofar and Universal projects to MC-S; and Coordenação de Aperfeiçoamento de Pessoal de Nível Superior (CAPES). GM is post-doctorate researcher at the Graduation Program in Biological Sciences: Physiology and Pharmacology, UFMG and holds a CNPq fellowship. LB is a recipient of CAPES PhD fellowship at the Post-graduation Program in Biological Sciences: Biochemistry and Immunology, UFMG.

\section{SUPPLEMENTARY MATERIAL}

The Supplementary Material for this article can be found online at http://www.frontiersin.org/articles/10.3389/fimmu.2018.00058/ full\#supplementary-material.

15. Santos RA, Ferreira AJ, Verano-Braga T, Bader M. Angiotensin-converting enzyme 2, angiotensin-(1-7) and Mas: new players of the renin-angiotensin system. J Endocrinol (2013) 216:R1-17. doi:10.1530/JOE-12-0341

16. Donoghue M, Hsieh F, Baronas E, Godbout K, Gosselin M, Stagliano N, et al. A novel angiotensin-converting enzyme-related carboxypeptidase (ACE2) converts angiotensin I to angiotensin 1-9. Circ Res (2000) 87(5):E1-9. doi:10.1161/01.RES.87.5.e1

17. Tipnis SR, Hooper NM, Hyde R, Karran E, Christie G, Turner AJ. A human homolog of angiotensin-converting enzyme. Cloning and functional expression as a captopril-insensitive carboxypeptidase. J Biol Chem (2000) 275(43):33238-43. doi:10.1074/jbc.M002615200

18. Santos RA, Simoes e Silva AC, Maric C, Silva DM, Machado RP, de Buhr I, et al. Angiotensin-(1-7) is an endogenous ligand for the $G$ protein-coupled receptor Mas. Proc Natl Acad Sci U S A (2003) 100(14):8258-63. doi:10.1073/ pnas. 1432869100

19. Simoes e Silva AC, Silveira KD, Ferreira AJ, Teixeira MM. ACE2, angiotensin-(1-7) and Mas receptor axis in inflammation and fibrosis. Br J Pharmacol (2013) 169:477-92. doi:10.1111/bph.12159

20. MagalhãesGS, Rodrigues-MachadoMG,Motta-SantosD,SilvaAR, CaliariMV, Prata LO, et al. Angiotensin-(1-7) attenuates airway remodelling and hyperresponsiveness in a model of chronic allergic lung inflammation. Br J Pharmacol (2015) 172(9):2330-42. doi:10.1111/bph.13057

21. Rodrigues-Machado MG, Magalhães GS, Cardoso JA, Kangussu LM, Murari A, Caliari MV, et al. AVE 0991, a non-peptide mimic of angiotensin-(1-7) effects, attenuates pulmonary remodelling in a model of chronic asthma. Br J Pharmacol (2013) 170(4):835-46. doi:10.1111/bph.12318

22. Bennion DM, Rosado CA, Haltigan EA, Regenhardt RW, Sumners C, Waters MF. Serum activity of angiotensin converting enzyme 2 is decreased in patients with acute ischemic stroke. J Renin Angiotensin Aldosterone Syst (2016) 17(3):1-7. doi:10.1177/1470320316661060

23. Li W, Li J, Hao P, Chen W, Meng X, Li H, et al. Imbalance between angiotensin II and angiotensin-(1-7) in human coronary atherosclerosis. J Renin Angiotensin Aldosterone Syst (2016) 17(3):1-6. doi:10.1177/1470320316659618

24. Shenoy V, Ferreira AJ, Qi Y, Fraga-Silva RA, Díez-Freire C, Dooies A, et al. The angiotensin-converting enzyme 2/angiogenesis-(1-7)/Mas axis confers cardiopulmonary protection against lung fibrosis and pulmonary hypertension. Am J Respir Crit Care Med (2010) 182:1065-72. doi:10.1164/ rccm.200912-1840OC

25. Li Y, Zeng Z, Cao Y, Liu Y, Ping F, Liang M, et al. Angiotensin-converting enzyme 2 prevents lipopolysaccharide-induced rat acute lung injury via suppressing the ERK1/2 and NF-kappaB signaling pathways. Sci Rep (2016) 6:27911. doi:10.1038/srep27911

26. da Silveira KD, Coelho FM, Vieira AT, Sachs D, Barroso LC, Costa VV, et al. Anti-inflammatory effects of the activation of the angiotensin-(1-7) receptor, 
Mas, in experimental models of arthritis. J Immunol (2010) 185(9):5569-76. doi:10.4049/jimmunol.1000314

27. Magalhaes GS, Rodrigues-Machado MG, Motta-Santos D, Alenina N, Bader M, Santos RA, et al. Chronic allergic pulmonary inflammation is aggravated in angiotensin-(1-7) Mas receptor knockout mice. Am J Physiol Lung Cell Mol Physiol (2016) 311(6):L1141-8. doi:10.1152/ajplung.00029.2016

28. Marques FD, Ferreira AJ, Sinisterra RD, Jacoby BA, Sousa FB, Caliari MV, et al. An oral formulation of angiotensin-(1-7) produces cardioprotective effects in infarcted and isoproterenol-treated rats. Hypertension (2011) 57(3):477-83. doi:10.1161/HYPERTENSIONAHA.110.167346

29. Strath M, Warren DJ, Sanderson CJ. Detection of eosinophils using an eosinophil peroxidase assay. Its use as an assay for eosinophil differentiation factors. J Immunol Methods (1985) 83:209-15. doi:10.1016/0022-1759 (85) $90242-\mathrm{X}$

30. Godson C, Mitchell S, Harvey K, Petasis NA, Hogg N, Brady HR. Cutting edge: lipoxins rapidly stimulate non-phlogistic phagocytosis of apoptotic neutrophils by monocyte-derived macrophages. J Immunol (2000) 164(4):1663-7. doi:10.4049/jimmunol.164.4.1663

31. Dalli J, Serhan CN. Specific lipid mediator signatures of human phagocytes: microparticles stimulate macrophage efferocytosis and pro-resolving mediators. Blood (2012) 120(15):e60-72. doi:10.1182/blood-2012-04-423525

32. Sousa LP, Carmo AF, Rezende BM, Lopes F, Silva DM, Alessandri AL, et al. Cyclic AMP enhances resolution of allergic pleurisy by promoting inflammatory cell apoptosis via inhibition of PI3K/Akt and NF-kappaB. Biochem Pharmacol (2009) 78(4):396-405. doi:10.1016/j.bcp.2009.04.030

33. Fujihara S, Jaffray E, Farrow SN, Rossi AG, Haslett C, Hay RT. Inhibition of NF-kappa B by a cell permeable form of I kappa B alpha induces apoptosis in eosinophils. Biochem Biophys Res Commun (2005) 326(3):632-7. doi:10.1016/j. bbrc.2004.11.090

34. Sousa LP, Lopes F, Silva DM, Tavares LP, Vieira AT, Rezende BM, et al. PDE4 inhibition drives resolution of neutrophilic inflammation by inducing apoptosis in a PKA-PI3K/Akt-dependent and NF-kappaB-independent manner. J Leukoc Biol (2010) 87(5):895-904. doi:10.1189/jlb.0809540

35. El-Hashim AZ, Renno WM, Raghupathy R, Abduo HT, Akhtar S, Benter IF. Angiotensin-(1-7) inhibits allergic inflammation, via the MAS1 receptor, through suppression of ERK1/2- and NF-kappaB-dependent pathways. Br J Pharmacol (2012) 166(6):1964-76. doi:10.1111/j.1476-5381. 2012.01905.x

36. El-Hashim AZ, Renno WM, Abduo HT, Jaffal SM, Akhtar S, Benter IF. Effect of inhibition of the ubiquitinproteasome-system and IkappaB kinase on airway inflammation and hyperresponsiveness in a murine model of asthma. Int JImmunopathol Pharmacol (2011) 24:33-42. doi:10.1177/ 039463201102400105
37. Alam R, Gorska MM. Mitogen-activated protein kinase signaling and ERK1/2 bistability in asthma. Clin Exp Allergy (2011) 41(2):149-59. doi:10.1111/j.1365-2222.2010.03658.x

38. Yamashita M, Shinnakasu R, Asou H, Kimura M, Hasegawa A, Hashimoto K, et al. Ras-ERK MAPK cascade regulates GATA3 stability and Th2 differentiation through ubiquitin-proteasome pathway. J Biol Chem (2005) 280(33):29409-19. doi:10.1074/jbc.M502333200

39. Murdoch JR, Lloyd CM. Chronic inflammation and asthma. Mutat Res (2010) 690:24-39. doi:10.1016/j.mrfmmm.2009.09.005

40. Nakamura Y, Ghaffar O, Olivenstein R, Taha RA, Soussi-Gounni A, Zhang DH, et al. Gene expression of the GATA3 transcription factor is increased in atopic asthma. JAllergy Clin Immunol (1999) 103:215-22. doi:10.1016/ S0091-6749(99)70493-8

41. Jousilahti P, Salomaa V, Hakala K, Rasi V, Vahtera E, Palosuo T. The association of sensitive systemic inflammation markers with bronchial asthma. Ann Allergy Asthma Immunol (2002) 89(4):381-5. doi:10.1016/ S1081-1206(10)62039-X

42. Olafsdottir IS, Gislason T, Thjodleifsson B, Olafsson I, Gislason D, Jogi R, et al. C-reactive protein levels are increased in nonallergic but not allergic asthma: a multicentre epidemiological study. Thorax (2005) 60(6):451-4. doi:10.1136/thx.2004.035774

43. Takemura M, Matsumoto H, Nilmi A, Ueda T, Matsuoka H, Yamaguchi M, et al. High sensitivity C-reactive protein in asthma. Eur Respir J (2006) 27(5):908-12. doi:10.1183/09031936.06.00114405

44. Girdhar A, Kumar V, Singh A, Menon B, Vijayan VK. Systemic inflammation and its response to treatment in patients with asthma. Respir Care (2011) 56(6):800-5. doi:10.4187/respcare. 00601

45. Tay TR, Hew M. Comorbid "treatable traits" in difficult asthma: current evidence and clinical evaluation. Allergy (2017):1-14. doi:10.1111/all.13370

Conflict of Interest Statement: The authors declare that the research was conducted in the absence of any commercial or financial relationships that could be construed as a potential conflict of interest.

Copyright $\odot 2018$ Magalhaes, Barroso, Reis, Rodrigues-Machado, Gregório, MottaSantos, Oliveira, Perez, Barcelos, Teixeira, Santos, Pinho and Campagnole-Santos. This is an open-access article distributed under the terms of the Creative Commons Attribution License (CC BY). The use, distribution or reproduction in other forums is permitted, provided the original author(s) and the copyright owner are credited and that the original publication in this journal is cited, in accordance with accepted academic practice. No use, distribution or reproduction is permitted which does not comply with these terms. 